\title{
Differential contribution of protein phosphatase $1 \alpha$ to cell transformation of different cell types
}

\author{
JO-MEI MAUREEN CHEN ${ }^{1 *}$, KUN-CHIEH CHEN ${ }^{2,3^{*}}$, SHAO-CHIH CHIU $^{4,5^{*}}$, RU-YI CHEN $^{1 *}$, \\ JIUN-YI HSIA ${ }^{6,7^{*}}$, YUN-RU JAOYING HUANG ${ }^{1}$ and CHANG-TZE RICKY YU ${ }^{1}$
}

\begin{abstract}
${ }^{1}$ Department of Applied Chemistry, National Chi Nan University, Puli, Nantou 54561; ${ }^{2}$ Division of Chest Medicine, Department of Internal Medicine, Taichung Veterans General Hospital, Taichung 40705; ${ }^{3}$ Department of Life Sciences, National Chung Hsing University, Taichung 40227; ${ }^{4}$ Center for Neuropsychiatry, China Medical University Hospital;

${ }^{5}$ Graduate Institute of Immunology, China Medical University, Taichung 40447; ${ }^{6}$ Department of Surgery, Chung Shan Hospital, Tapei 10685; ${ }^{7}$ School of Medicine, Chung Shan Medical University, Taichung 40201, Taiwan, R.O.C.
\end{abstract}

Received February 13, 2019; Accepted July 15, 2019

DOI: $10.3892 /$ or.2019.7272

\begin{abstract}
Protein phosphorylation plays roles in cell transformation. Numerous protein kinase enzymes actively participate in the formation of various types of cancer by phosphorylating downstream substrates. Aurora-A is a widely known Serine/Threonine (Ser/Thr) oncogenic kinase, which is upregulated in more than twenty types of human cancer. This enzyme phosphorylates a wide range of substrates. For example, Aurora-A induces cell transformation by phosphorylating hepatoma upregulated protein (HURP) at four serine residues, which in turn decreases the phosphorylated levels of cell-growth suppressive Jun N-terminal kinase (p-JNK). Various protein phosphatase enzymes are considered tumor suppressors by the dephosphorylation and consequent inactivation of their oncogenic substrates. Protein phosphatase $1 \alpha$ (PP1 $\alpha$ ), for instance, acts on Aurora-A by dephosphorylating its substrates. However, the role of PP1 $\alpha$ in cancer progression remains ambiguous. PP1 $\alpha$ is overexpressed in several cancer tissues, and induces cell apoptosis and differentiation or it inhibits tumor formation in other types of cells. In addition, positive and negative correlations between PP1 $\alpha$ expression and lung cancer development have been documented. These observations suggest the differential regulation of PP1 $\alpha$ in various cancer tissues, or propose an ambiguous contribution of PP1 $\alpha$ to lung cancer development. In order to investigate these contradictory conclusions, it was reported that the chromosomal region covering the PPI $\alpha$ locus was subjected to DNA alterations, such as gain or loss in various human cancer
\end{abstract}

Correspondence to: Dr Chang-Tze Ricky Yu, Department of Applied Chemistry, National Chi Nan University, 1 University Road, Puli, Nantou 54561, Taiwan, R.O.C.

E-mail: ctyu@ncnu.edu.tw

*Contributed equally

Key words: PP1 $\alpha$, Aurora-A, HURP, AKT, JNK, lung cancer types by a study based on literature search. Upregulation of PP1 $\alpha$ was noted in a collection of lung cancer tissues, and was required for the cell transformation of the lung cancer cell line A549. In contrast to this finding, overexpression of ectopic PP1 $\alpha$ inhibited cell proliferation in 293T cells. Mechanistic studies revealed that PP1 $\alpha$ activated AKT in A549 cells, whereas it further inactivated AKT and disrupted the HURP/JNK signaling cascade in 293T cells. Collectively, the data indicated that PP1 $\alpha$ exerted an oncogenic function in lung cancer, while exhibiting various effects on cell transformation in different types of cells via distinct or opposite mechanisms.

\section{Introduction}

It is well established that a variety of protein kinases induce cell transformation by phosphorylating downstream protein substrates. For example, Aurora-A is a Serine/Threonine (Ser/Thr) kinase and a widely known oncoprotein associated with the development of numerous human cancers. Aurora-A transforms cells (1-3) by phosphorylating a wide range of downstream substrates $(4,5)$. For example, Aurora-A phosphorylates hepatoma upregulated protein (HURP) at four serine residues $(6,7)$. This process relays the cell transforming activity from Aurora-A to HURP (6,7).

In contrast to these findings, protein phosphatases, which remove phosphate groups from protein substrates result in the prevention or termination of kinase-induced cell proliferative signals and therefore are usually considered as tumor suppressors (8). However, the role of the Ser/Thr phosphatase protein phosphatase $1 \alpha(\mathrm{PP} 1 \alpha)$ in tumor progression remains undetermined. $\mathrm{PP} 1 \alpha$ has been revealed to prevent oncogenic transformation in NIH3T3 fibroblasts (9). PP1 $\alpha$ activity is detrimental to cell growth by causing activation of Rb-dependent G1 arrest in bone osteosarcoma cells $(10,11)$ and induction of apoptosis in $\mathrm{T}$ and fibroblast cells (12-15). In contrast to these observations, PP1 $\alpha$ is overexpressed in ascites hepatoma (16-18), prostate cancer (19), diffuse large B-cell lymphoma (20), and oral squamous cell carcinoma cell lines (21). These studies seemingly indicate a differential influence of PP1 $\alpha$ on different cancer types. Moreover, the 
contribution of PP1 $\alpha$ to lung cancer remains ambiguous. For example, PP1 $\alpha$ was revealed to be involved in the RIF1-induced tumor growth of the lung cancer cell line H1299 (22), while overexpression of PP1 $\alpha$ in H1299 cells restricted tumor formation in vivo (23). Furthermore, downregulation or inactivation of PP1 $\alpha$ was revealed to be associated with poor prognosis (24) and radioresistance (25) of lung cancer cells.

Numerous signaling cascades are regulated from protein kinases or protein phosphatases during cancer formation. The MAPK pathway and the AKT cascade are frequently altered in human cancer types $(26,27)$. The mitogen activated protein kinase (MAPK) superfamily consists of the ERK, p38 and Jun N-terminal kinase (JNK) proteins, and functions by transmitting upstream signals to its downstream effectors, thereby regulating several aspects of cancer development $(26,28)$. ERK and p38 are engaged in oncogenic processes, whereas JNK demonstrates an oncosuppressive role. Furthermore, AKT is activated by PI3K/PDK1 and inactivated by PTEN. The activation of AKT leads to the activation and/or the inactivation of a variety of downstream effectors, such as cyclin D1, and GSK3 $\beta$ or c-Raf, respectively $(27,29-31)$.

To explore the role of PP1 $\alpha$ in lung cancer and determine whether PP1 $\alpha$ contributes to cell proliferation or transformation according to each tissue type, it was examined by literature review whether the DNA region covering the PPla locus was subjected to frequent alterations, such as gain or loss in various types of cancer. Certain studies demonstrated that PP1 $\alpha$ was upregulated in lung cancer tissues, and that it was required for the cell transforming activity of the lung cancer cell line A549 by activating the AKT signaling pathway. However, PP1 $\alpha$ inhibited $293 \mathrm{~T}$ cell proliferation by regulating the JNK and AKT cascades. Collectively, the data indicated that PP1 $\alpha$ contributes to lung cancer formation and that it exhibits differential growth-stimulating effects in different cell types via distinct mechanisms of action.

\section{Materials and methods}

Chemicals, antibodies, plasmids and shRNAs. Fetal bovine serum (FBS), Dulbecco's modified Eagle's medium (DMEM), penicillin, streptomycin, and Lipofectamine ${ }^{\mathrm{TM}}$ were purchased from GIBCO-BRL; Thermo Fisher Scientific, Inc. The catalog numbers and suppliers for the antibodies used in the present study are as follows: PP1 $\alpha$ (cat. no. sc-271762), GFP (cat. no. sc-9996), tubulin (cat. no. sc-5286), actin (cat. no. sc-8432) and NF- $\mathrm{BB}$ (cat. no. sc-8008; all from Santa Cruz Biotechnology, Inc.); cyclin E1 (HPA018169; Sigma-Aldrich; Merck KGaA); GAPDH (cat. no. sc-32233; Santa Cruz Biotechnology, Inc.); phospho-AKT pathway sampler kit, (AKT, AKT p308, AKT p473, phospho-c-Raf, phospho-GSK3 $\beta$, phospho-PTEN, phospho-PDK1; cat. no. 9916), MAPK family sampler kit, (ERK, p38, JNK; cat. no. 9926), and phospho-MAPK family antibody sampler kit, (phospho-ERK, phospho-p38, phospho-JNK; cat. no. 9910; all from Cell Signaling Technology, Inc.); GSK3 $\beta$ (cat. no. sc-53931), c-Raf (cat. no. sc-52827) and PTEN (cat.no. sc-7974; all from Santa Cruz Biotechnology, Inc.). The antibodies against PP1 $\alpha$, tubulin, and actin, were purchased from Santa Cruz Biotechnology, Inc., and the antibodies against
AKT or MAPK pathways were purchased from Cell Signaling Technology, Inc. The p-HURP antibodies were generated by immunizing rabbits with synthesized peptides containing phospho-Ser as follows: p627, VKLFSGLSVSSEGP; p725, CLSSERMSLPLLA; p757, EGMELNSSITSQDV; p830, EHARH ISFGGNLI. All the antisera were further purified by antigenic peptide-bound column. EGFP-PP1 $\alpha$ was obtained from Dr Monique Beullens (51). The shRNAs used in the study were obtained from the National RNAi Core Facility at Academia Sinica in Taiwan and the targeting sequence for LacZ and PP1 $\alpha$ was CGCGATCGTAATCACCCGAGT and TGAGTGCAAGAGACGCTACAA respectively.

Tissue procurement. The study protocol in terms of the collection of the biopsies of patients was approved by the Ethics Committee at Taichung Veterans General Hospital. No patient had previously received any neoadjuvant treatment such as chemotherapy before surgery. Patients (31) were recruited from $2004 / 4 / 7$ to $2005 / 12 / 28$ in the study with males accounting for $71 \%$, and a mean age of 65 ranging from 41 to 87 . All patients provided informed consent and signed the consent form individually. The study samples were obtained after surgery from a non-necrotic area of the tumor and from adjacent non-tumorous tissue from neighboring sites outside the tumor. Both tumor and adjacent non-tumor tissues were confirmed by pathologists. The tissue samples were placed immediately in cryovials, frozen in liquid nitrogen, and stored at $-80^{\circ} \mathrm{C}$ until analysis by western blotting.

Cell culture. The cell lines used in this study were purchased from the American Type Culture Collection. The culture medium for 293T cells was Dulbecco/Vogt Modified Eagle's Minimal Essential Medium with 5\% fetal bovine serum, and for A549 cells it was Roswell Park Memorial Institute (RPMI)-1640 medium with $10 \%$ fetal bovine serum, $1 \%$ nonessential amino acids, and $1 \%$ sodium pyruvate. Moreover, $2 \mathrm{mM}$ glutamine, $100 \mathrm{U} / \mathrm{ml}$ penicillin, and $100 \mathrm{~g} / \mathrm{ml}$ streptomycin were added in all media. All cell culture-related reagents were purchased from Invitrogen; Gibco; Life Technologies; Thermo Fisher Scientific, Inc. Cells were maintained in a humidified incubator at $37^{\circ} \mathrm{C}$ in the presence of $5 \% \mathrm{CO}_{2}$.

Single cell proliferation assay. The assay was based on our previous study (22). Briefly, cells were seeded in 24-well plates and transfected with desired constructs tagged with EGFP. The following day, the cells were replated with low density to $10-\mathrm{cm}$ dishes, to prevent cell contact. The cells were allowed to proliferate for 1-4 days, and the percentage of cells with proliferation judged by formation of 'mini-colonies' with cell numbers $\geq 2$ was counted. If cells could not proliferate, they remained single in the $10-\mathrm{cm}$ dish after 36 -h culture.

Colony formation assay. Cells $\left(2 \times 10^{3}\right)$ were seeded in $10-\mathrm{cm}$ dishes and cultured for 10 days. The cell foci were fixed with methanol and stained with 5\% Giemsa solution. The focus number was then counted.

PolyHEMA-based anchorage-independent growth. PolyHEMA $(2.5 \mathrm{mg} / \mathrm{ml})$ was added to $6-\mathrm{cm}$ dishes and 
Table I. The DNA alteration covering PP1 $\alpha$ locus 11q13.2 in various cancer tissues.

\begin{tabular}{|c|c|c|c|}
\hline Altered DNA region & Cancer types & DNA alteration & (Refs.) \\
\hline llql3.2 & Esophageal squamous cell carcinoma & Amplification & $(32)$ \\
\hline llq13.2 & Esophageal squamous cell carcinoma & Amplification & $(33)$ \\
\hline 1lq13.2 & Esophageal squamous cell carcinoma & Amplification & $(34)$ \\
\hline 1lq13.2 & Intrahepatic cholangiocarcinoma & Amplification & $(43)$ \\
\hline 1lq13.2 & Hepatocellular carcinoma & Amplification & $(44)$ \\
\hline llq13.2 & Colorectal cancer & Amplification & $(49)$ \\
\hline llq13.2 & Myeloid leukemia & Amplification & $(37)$ \\
\hline llq13.2 & Plasmablastic lymphoma & Amplification & $(46)$ \\
\hline llq13.2 & Myeloid leukemia & Amplification & $(47)$ \\
\hline 1lq13.2 & Ovanan cancer & Amplification & $(35)$ \\
\hline 1lq13.2 & Ovanan cancer & Deletion & $(36)$ \\
\hline llql3.2 & Prostate cancer & Amplification & $(38)$ \\
\hline llq13.2 & Prostate cancer & Amplification & (39) \\
\hline llq13.2 & Breast cancer & Amplification & $(40)$ \\
\hline 1lq13.2 & Breast carcinoma & Deletion & $(41)$ \\
\hline llql3.2 & Invasive lobular carcinoma & Amplification & $(45)$ \\
\hline 1lq13.2 & Urothelial carcinoma & Amplification & $(42)$ \\
\hline llq13.2 & Peritoneal mesothelioma & Deletion & $(48)$ \\
\hline llq13.2 & Skin cancer & Amplification & $(50)$ \\
\hline
\end{tabular}

PP1 $\alpha$, protein phosphatase $1 \alpha$.

heated on a hotplate until most of the solution evaporated. The coated dishes were sterilized under UV irradiation before use. Cells $\left(5 \times 10^{5}\right)$ were then seeded onto the dishes and allowed attachment and proliferation for 2 days. The cells were trypsinized and counted with a hemocytometer.

Migration wound healing assays. Cells with full confluence were incubated with serum-free medium for overnight. The cells were then scraped with a $20-\mu l$ gel-loading tip to create an empty space which allows for cell migration. Serum containing the medium was then added to cells and the migrated cells were photographed at $0,3,6$ and $9 \mathrm{~h}$ with an CCD camera (Olympus, Model DP71) attached to an inverted microscope (Olympus Optical Co., Ltd., Tokyo, Japan). The cells with migration were counted.

Preparation of cell extracts and western blot analysis. To prepare the cell-free extracts, cells were lysed in extraction buffer (20 mM PIPES, pH 7.2, 100 mM NaCl, 1 mM EDTA, $0.1 \%$ CHAPS, $10 \%$ sucrose, $1 \mathrm{mM}$ PMSF, $1 \mathrm{mM}$ DTT, $1 \mathrm{mM}$ $\mathrm{Na} 3 \mathrm{VO} 4$, and $10 \mu \mathrm{g} / \mathrm{ml}$ each of leupeptin, aprotinin, chymostatin, and pepstatin). After incubation at $4^{\circ} \mathrm{C}$ for $30 \mathrm{~min}$, cellular debris was removed by centrifugation at $15,856 \mathrm{x} \mathrm{g}$ for $90 \mathrm{~min}$ in an Eppendorf centrifuge. Protein concentrations were determined using the Bradford assay (Bio-Rad Laboratories, Inc.). The resulting samples were heated at $95^{\circ} \mathrm{C}$ for $10 \mathrm{~min}$ and loaded onto a $10 \%$ SDS-polyacrylamide electrophoresis gel (SDS-PAGE) and then transferred onto a polyvinylidene difluoride membrane (PVDF; EMD Millipore). The PVDF membrane was then blocked with $5 \%$ bovine serum albumin (BSA)/PBST ( $0.1 \%$ Tween-20 in
PBS). Various antibodies were incubated with the membranes at $4^{\circ} \mathrm{C}$ for overnight. The membranes were washed with PBST at room temperature for $30 \mathrm{~min}$ and repeated for 3 times. Secondary antibodies against mouse (cat. no. sc-2005) or rabbit (cat. no. sc-2004) IgG conjugated with horseradish peroxidase (Santa Cruz Biotechnology, Inc.) were added for $1 \mathrm{~h}$ at room temperature followed by washing with PBST for $3 \times 30$ min. NBT and BCIP substrates (Zymed Laboratories, Inc.) were added to develop the membrane. The protein level was assessed using the software (Gel-Pro analyzer 4.5), and the signal intensity of the protein of interest was normalized against that of actin, tubulin, or GAPDH. When comparing the changes of protein between the control and experimental groups, a relative level of each protein of interest was used, where [protein of interest/actin] experimental was normalized with [protein of interest/actin] $]_{\text {control }}$.

Immunoprecipitation. One milligram of cell extracts with protease inhibitors were incubated with protein $\mathrm{A} / \mathrm{G}$ beads in $500 \mu \mathrm{l}$ immunoprecipitation washing buffer (50 mM HEPES, $\mathrm{pH}$ 7.6, $2 \mathrm{mM} \mathrm{MgCl}_{2}, 50 \mathrm{mM} \mathrm{NaCl}, 5 \mathrm{mM}$ EGTA, 0.1\% Triton $\mathrm{X}-100,40 \mathrm{mM}$ glycerolphosphate) at $4^{\circ} \mathrm{C}$, for $1 \mathrm{~h}$, to preabsorb unwanted proteins. Antibodies in the amount of $1 \mu \mathrm{g}$ were then added to the cell extracts for $4 \mathrm{~h}$ at $4^{\circ} \mathrm{C}$. The cell extracts were then incubated with protein $\mathrm{A} / \mathrm{G}$-beads for $1 \mathrm{~h}$, followed by 6 washes with PBS for $3 \mathrm{~h}$ at $4^{\circ} \mathrm{C}$. The resulting samples were heated at $95^{\circ} \mathrm{C}$ for $10 \mathrm{~min}$ and applied to SDS-PAGE-based electrophoresis and western blotting.

Statistical analysis. All data were collected from three independent experiments and presented as the mean \pm SD. 

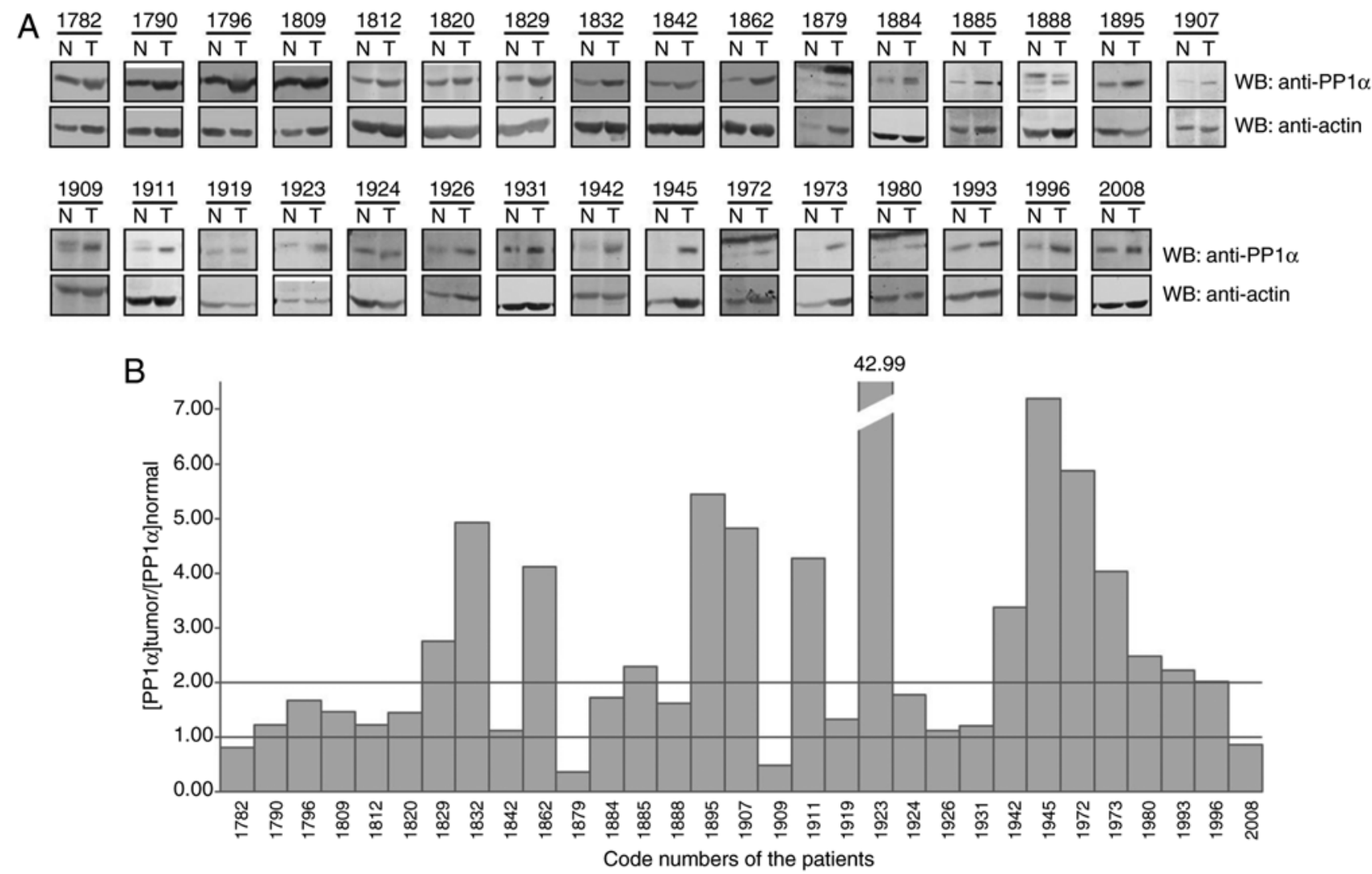

Figure 1. PP1 $\alpha$ is upregulated in lung cancer tissues. Protein expression of PP1 $\alpha$ in a collection of 31 samples of lung cancer tissue. (A) Biopsies from paired lung tumor $(\mathrm{T})$ and adjacent normal tissues $(\mathrm{N})$ were subjected to western blotting. (B) The quantification of PP1 $\alpha$ protein levels in the collected paired lung tissues is displayed. The numbers on the (A) N and T or (B) $\mathrm{x}$-axis represent the codes of the patients. The intensity of PP1 $\alpha$ or $\beta$-actin was quantified by densitometry. The levels of the PP1 $\alpha$ protein in each paired tissue were normalized against those of $\beta$-actin. The ratio of normalized PP1 $\alpha$ levels in the tumor tissues to those observed in the normal tissues was calculated and plotted in the lower image. PP1 $\alpha$, protein phosphatase $1 \alpha$.

Statistical significance determined by independent samples Student's t-tests were represented as $\mathrm{P}<0.05, \mathrm{P}<0.01$, and $\mathrm{P}<0.001$.

\section{Results}

PPla is upregulated in lung cancer tissues. In order to examine the potential involvement of PP1 $\alpha$ in cancer formation, we initially discovered that the DNA region covering the PPI $\alpha$ locus, i.e. 11q13.2, was subjected to DNA alteration in various types of human cancer (Table I). The majority of these alterations were DNA amplifications. For example, in the digestive system the following cancer types were present: Esophageal squamous cell carcinoma, hepatocellular carcinoma and colorectal cancer, whereas in the immune system, myeloid leukemia and plasmablastic lymphoma were noted. Moreover, PP1 $\alpha$ protein levels were increased in lung cancer. At least, a 2-fold increase in PP1 $\alpha$ protein levels was observed in 15 out of 31 lung cancer pairs of cancerous and adjacent normal tissues (Fig. 1). These findings indicated that deregulation of PP1 $\alpha$ occurred concomitantly with cancer formation.

PPI $\alpha$ is required for the transformation of the A549 lung cancer cell line. To explore the role of $\mathrm{PP} 1 \alpha$ in lung cancer development, an ectopic overexpression model of PP1 $\alpha$ was initially performed in A549 cells, and it was further demon- strated that PP1 $\alpha$ could promote cell proliferation (Fig. 2A). Secondly, PP1 $\alpha$ expression was knocked down in A549 cells and the PP1 $\alpha$-depleted cells exhibited a considerably slower rate under normal or low serum conditions (Fig. 2B). Low growth was also observed in the presence of a cellular environment that would not allow strong attachment of the cells (Fig. 2C) and in the presence of a low number of cells (Fig. 2D). Moreover, A549 cells harboring a PPla shRNA sequence exhibited reduced migratory activity (Fig. 3). All these observations revealed that PP1 $\alpha$ was a potential oncoprotein in lung cancer cells.

PPI $\alpha$ activates the PDK1/AKT pathway. To explore the underlying mechanisms by which PP1 $\alpha$ causes cell transformation, the expression levels of the proteins involved in MAPK and/or the AKT signaling cascades were investigated (Fig. 4). Although PP1 $\alpha$ did not affect the MAPK pathway, the protein phosphatase regulated the AKT cascade. It was demonstrated that knockdown of PP1 $\alpha$ downregulated the levels of PDK1 and AKT p473, whereas it upregulated the levels of p-Gsk $3 \beta$ and p-c-Raf.

PPla inhibits cell proliferation of 2937 cells. In addition to the amplification of the chromosomal region nearby the $P P 1 \alpha$ locus 11q13.2, the data further indicated that $11 q 13.2$ was deleted in certain cancer types of sex hormone-dependent tissues, such as ovarian and breast cancer, and in other 


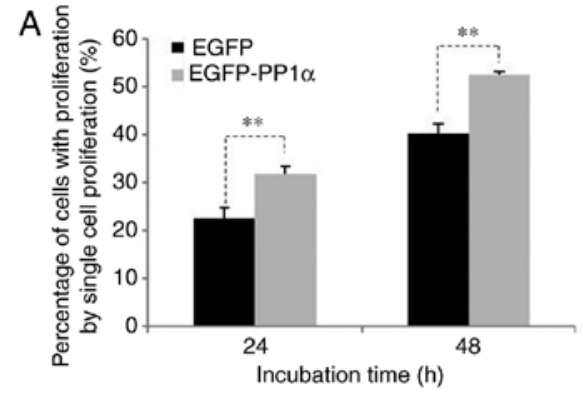

B

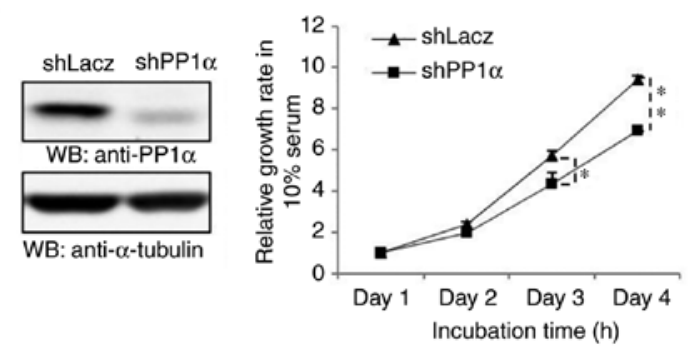

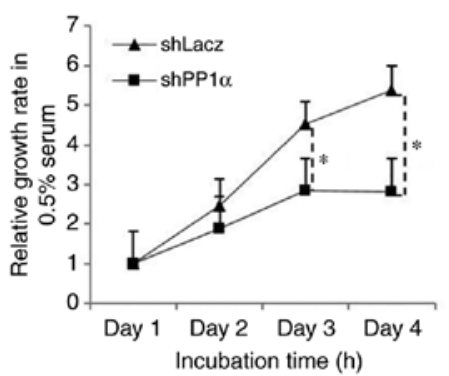
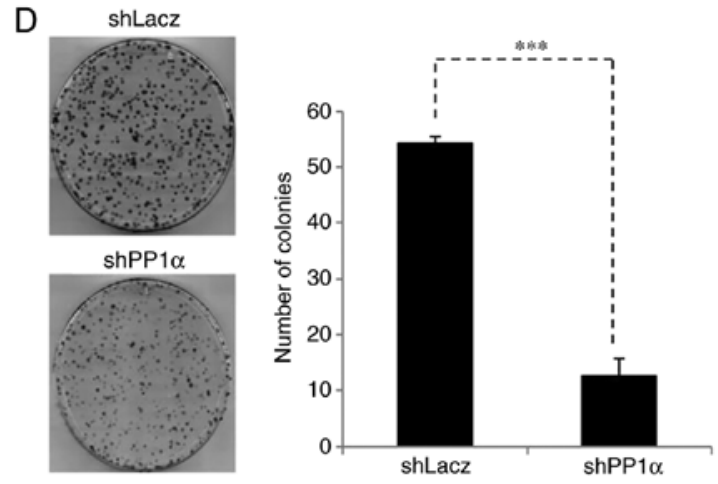

Figure 2. PP1 $\alpha$ is required for the cell transforming activity of A549 cells. (A) PP1 $\alpha$ stimulated cell proliferation in A549 cells. The cell proliferative activity of A549 cells transfected with EGFP or EGFP-PP1 $\alpha$ was assessed (see Materials and methods). The \% of proliferation was counted and plotted. (B) Knockdown of PP1 $\alpha$ impaired cell proliferation under normal or low serum conditions. A549 cells harboring LacZ shRNA (shLacZ) or PP1 $\alpha$ shRNA (shPP1 $\alpha$ ) were examined for the relative knockdown efficiency (left) and analyzed for cell proliferative activity by counting the number of cells using a hemocytometer in $10 \%$ (middle) or $0.5 \%$ (right) serum. (C) Knockdown of PP1 $\alpha$ impaired anchorage-independent growth. A549 cells harboring shLacZ or shPP1 $\alpha$ were analyzed for cell proliferative activity on polyHEMA-coated plates. (D) Knockdown of PP1 $\alpha$ reduced colony formation activity. A549 cells harboring shLacZ or shPP1 $\alpha$ were analyzed using the colony formation assay. All data were collected from three independent experiments with error bars representing the SD. " $\mathrm{P}<0.05$, ${ }^{* *} \mathrm{P}<0.01$ and ${ }^{* * *} \mathrm{P}<0.001$ represented significant differences as determined using Student's t-test, respectively. PP1 $\alpha$, protein phosphatase $1 \alpha$.
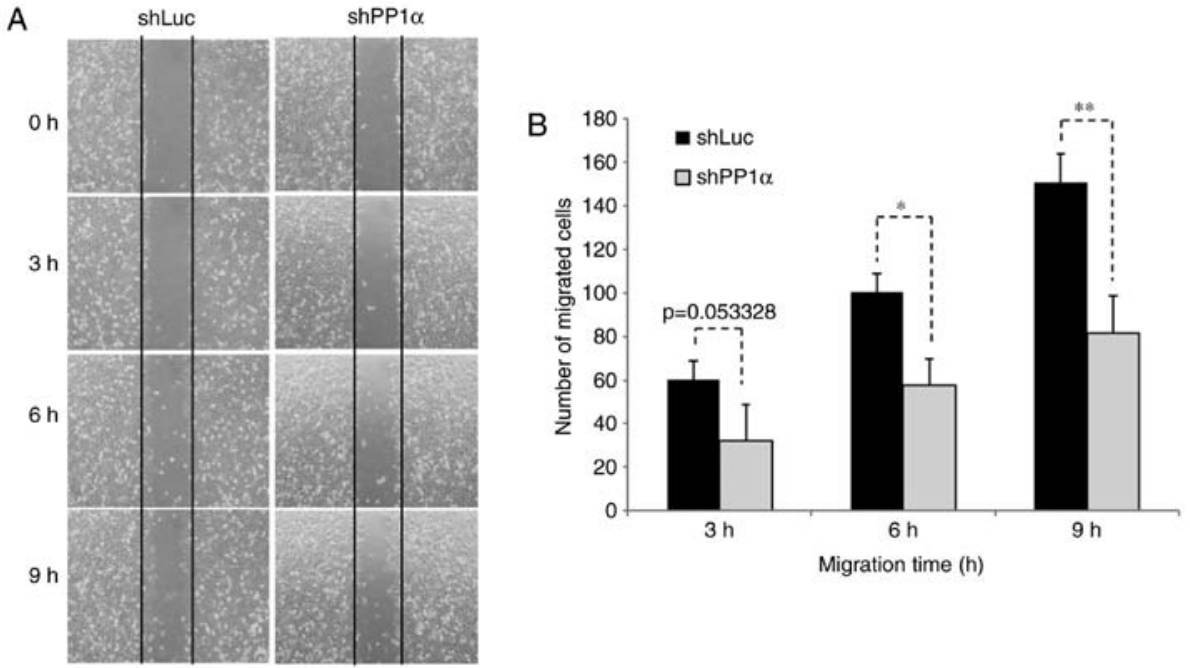

Figure 3. PP1 $\alpha$ is required for cell migration. (A) A549 cells harboring shLuc or shPP1 $\alpha$ were analyzed for cell migration by wound healing assay for 0-9 h. (B) The cells that migrated into the scraped wound were counted and plotted. The data were collected from three independent experiments with error bars representing the SD. ${ }^{*} \mathrm{P}<0.05$ and ${ }^{* *} \mathrm{P}<0.01$ represented significant differences as determined using Student's t-test, respectively. PP1 $\alpha$, protein phosphatase $1 \alpha$. 

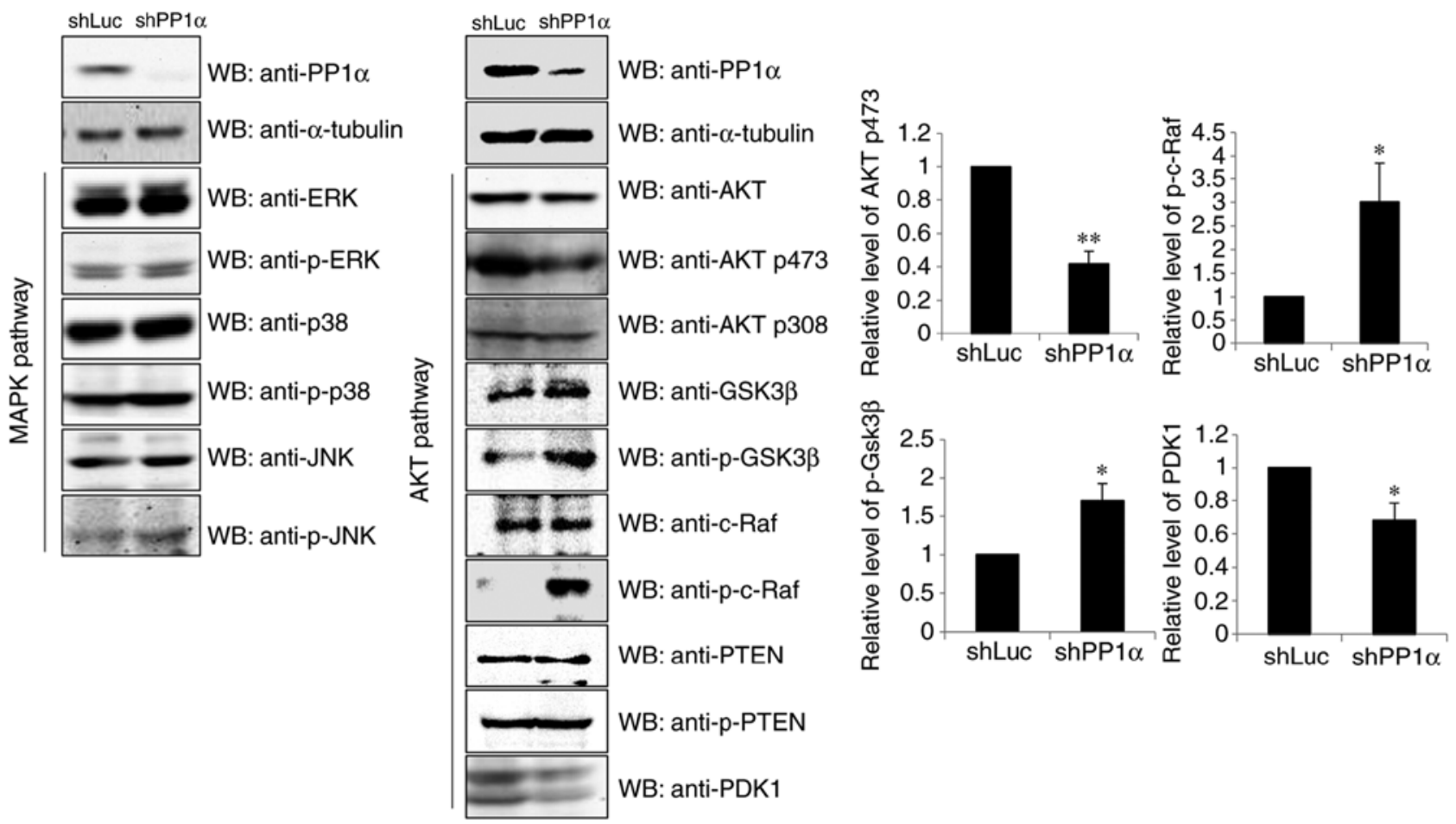

Figure 4. Effects of PP1 $\alpha$ on the MAPK or the AKT pathway. A549 cells harboring shLuc or shPP1 $\alpha$ were analyzed for the expression of the proteins involved in the MAPK or AKT pathways. The relative expression of each affected component was measured, calculated and plotted on the right of the Figure. The data were collected from three independent experiments with error bars representing the SD. ${ }^{*} \mathrm{P}<0.05$ and ${ }^{* * *} \mathrm{P}<0.01$ represented significant differences as determined using Student's t-test, respectively. $\mathrm{PP} 1 \alpha$, protein phosphatase $1 \alpha$.

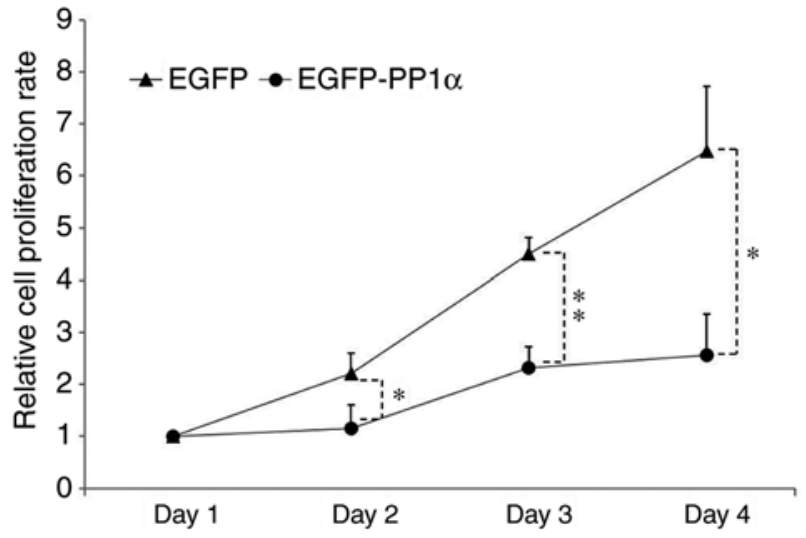

Figure 5. PP1 $\alpha$ inhibits cell growth in 293T cells. 293T cells were transfected with EGFP or EGFP-PP1 $\alpha$ and were assayed for cell proliferative activity for 1-4 days by the cell proliferation assay. The data were collected from three independent experiments with error bars representing the SD. and the symbols ${ }^{*} \mathrm{P}<0.05$ and ${ }^{* *} \mathrm{P}<0.01$ represented significant differences as determined using Student's t-test, respectively. PP1 $\alpha$, protein phosphatase $1 \alpha$.

cancer types, such as peritoneal mesothelioma (Table I). To examine whether PP1 $\alpha$ exerts a negative contribution to cell transformation, PP1 $\alpha$ was overexpressed in $293 \mathrm{~T}$ cells and it was demonstrated that the cell proliferative rate was largely impaired (Fig. 5).

PP1a regulates the dephosphorylation of the Aurora-A downstream substrate HURP. To explore the mechanism by which PP1 $\alpha$ retards cell proliferation, we expanded our analysis on the finding that PP1 $\alpha$ acted against Aurora-A by dephosphorylating its substrates. The previous studies conducted by our group established that Aurora-A could phosphorylate HURP and promote cell transformation $(6,7)$. Based on these findings the potential involvement of HURP was investigated in the PP1 $\alpha$-dependent inhibition of cell proliferation. It was initially revealed that $\mathrm{PP} 1 \alpha$ could interact with HURP (Fig. 6A). HURP is phosphorylated by Aurora-A during mitosis (7). Therefore, it was assessed whether the interaction of Aurora-A with PP1 $\alpha$ could reduce the phosphorylation levels of HURP. The data demonstrated that overexpression of PP1 $\alpha$ decreased the levels of the four p-HURP isoforms catalyzed by Aurora-A in untreated cells or nocodazole-induced mitosis (Fig. 6B), whereas knockdown of PP1 $\alpha$ exhibited the opposite effects (Fig. 6C). These isoforms were derived based on the type of the amino acid residue that was phosphorylated each time. It has been reported that the Aurora-A-induced phosphorylation of HURP stimulates cell proliferation by downregulating p-JNK (6). Therefore, the expression levels of JNK were investigated and it was demonstrated that PP1 $\alpha$ significantly increased the levels of p-JNK in $293 \mathrm{~T}$ cells (Fig. 7A). Notably, PP1 $\alpha$ did not affect p-JNK levels in A549 cells (Fig. 4), while it reduced the levels of AKT p473 in 293T cells (Fig. 7B), revealing a differential action of PP1 $\alpha$ in the two cell lines.

\section{Discussion}

The chromosomal region covering $P P l \alpha$ is subjected to DNA alterations in human cancers including amplification and deletion, which reflects the distinct effect of PP1 $\alpha$ on 
A

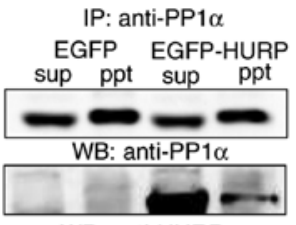

WB: anti-HURP

B

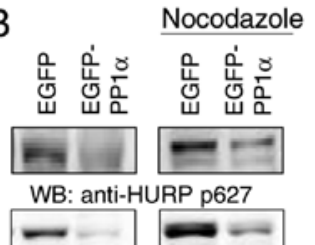

WB: anti-HURP p725
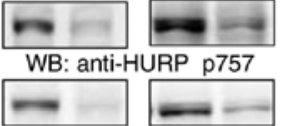

WB: anti-HURP p830
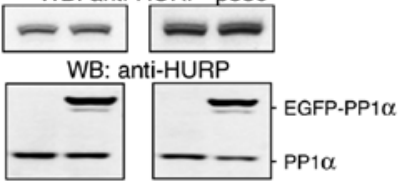

WB: anti-PP1 $\alpha$

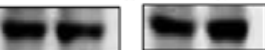

WB: anti-actin
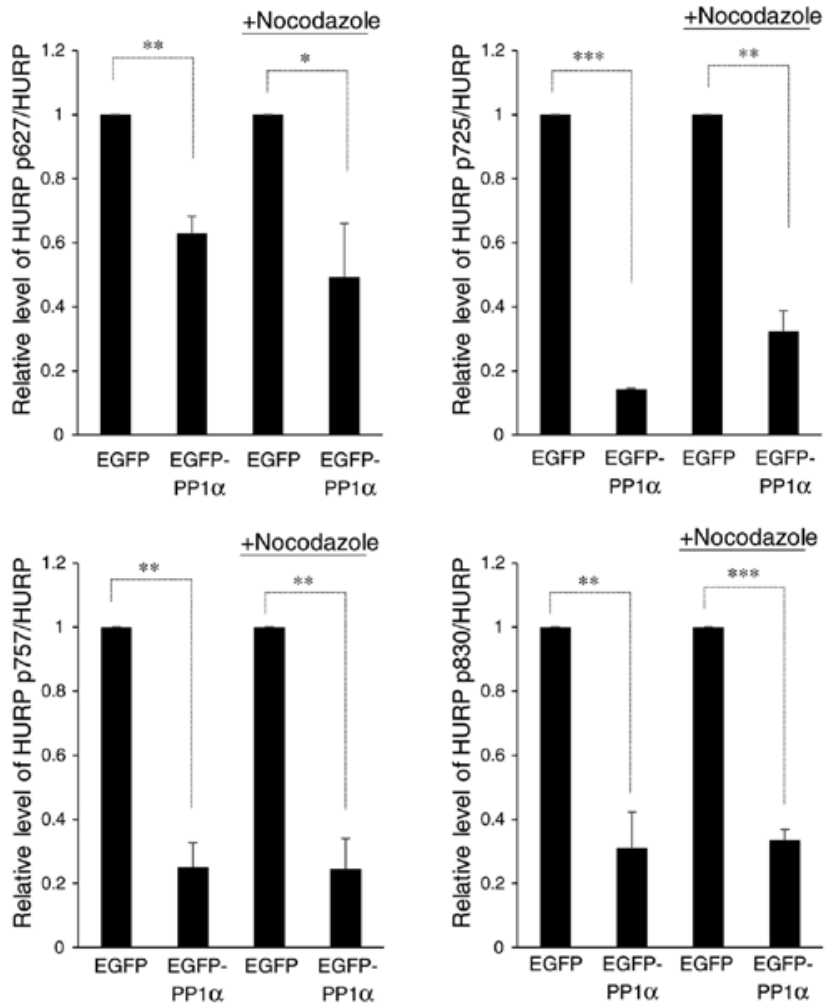

C

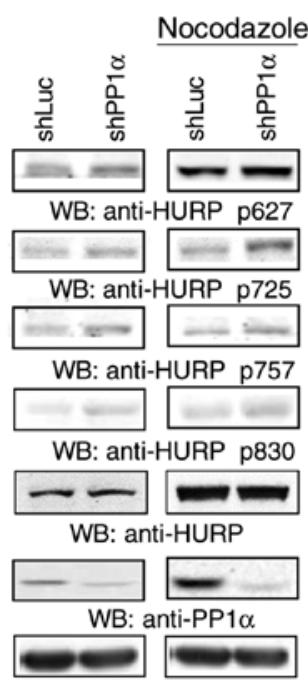

WB: anti-GAPDH
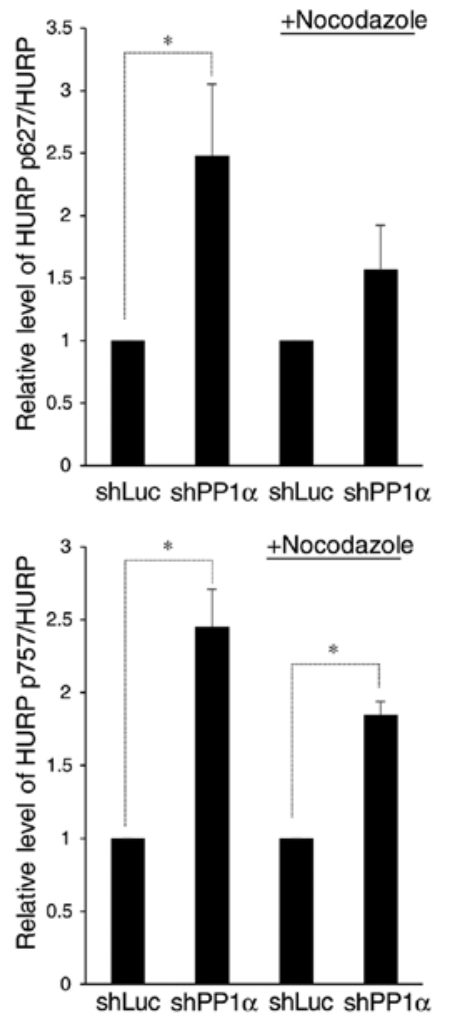
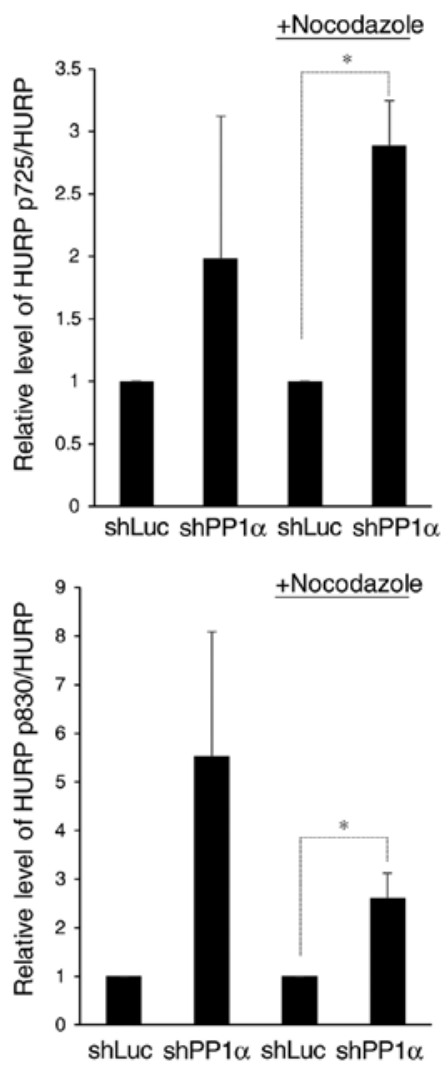

Figure 6. PP1 $\alpha$ interacts with HURP and controls the dephosphorylation of HURP. (A) PP1 $\alpha$ interacts with HURP. Immunoprecipitation using an antibody against PP1 $\alpha$ was conducted in 293T cells transfected with EGFP or EGFP-HURP. sup, supernatant; ppt, pellet. (B) Overexpression of PP1 $\alpha$ reduced the levels of p-HURP. 293T cells transfected with EGFP or EGFP-PP1 $\alpha$ were treated with or without nocodazole and they were subsequently analyzed for the expression levels of the four p-HURP isoforms at S627, S725, S757 and S830 residues. The levels of each p-HURP isoform and HURP in each treatment were measured, the ratio of p-HURP/HURP was calculated, and [p-HURP/HURP $]_{\text {EGFP-PPIa }} /[\mathrm{p}-\mathrm{HURP} / \mathrm{HURP}]_{\mathrm{EGFP}}$ was finally obtained and plotted. Since HURP may act at the mitotic phase, cells were treated with nocodazole in order to examine p-HURP levels during mitotic cell division. (C) Knockdown of PP1 $\alpha$ increased the levels of p-HURP. 293T cells harboring shLuc or shPP1 $\alpha$ were treated with or without nocodazole and subsequently analyzed for the levels of various p-HURPs. The levels of each $\mathrm{p}$-HURP isoform and HURP in each treatment were measured, the ratio of $\mathrm{p}-\mathrm{HURP} / \mathrm{HURP}$ was calculated, and $[\mathrm{p}-\mathrm{HURP} / \mathrm{HURP}]_{\mathrm{EGFP}-\mathrm{PPIa}} /[\mathrm{p}-\mathrm{HURP} / \mathrm{HURP}]_{\mathrm{EGFP}}$ was finally obtained and plotted. All data were collected from three independent experiments with error bars representing the $\mathrm{SD}$. ${ }^{*} \mathrm{P}<0.05,{ }^{* *} \mathrm{P}<0.01$ and ${ }^{* * * *} \mathrm{P}<0.001$ represented significant differences as determined using Student's t-test, respectively. PP1 $\alpha$, protein phosphatase 1 $\alpha$; HURP, hepatoma upregulated protein. 

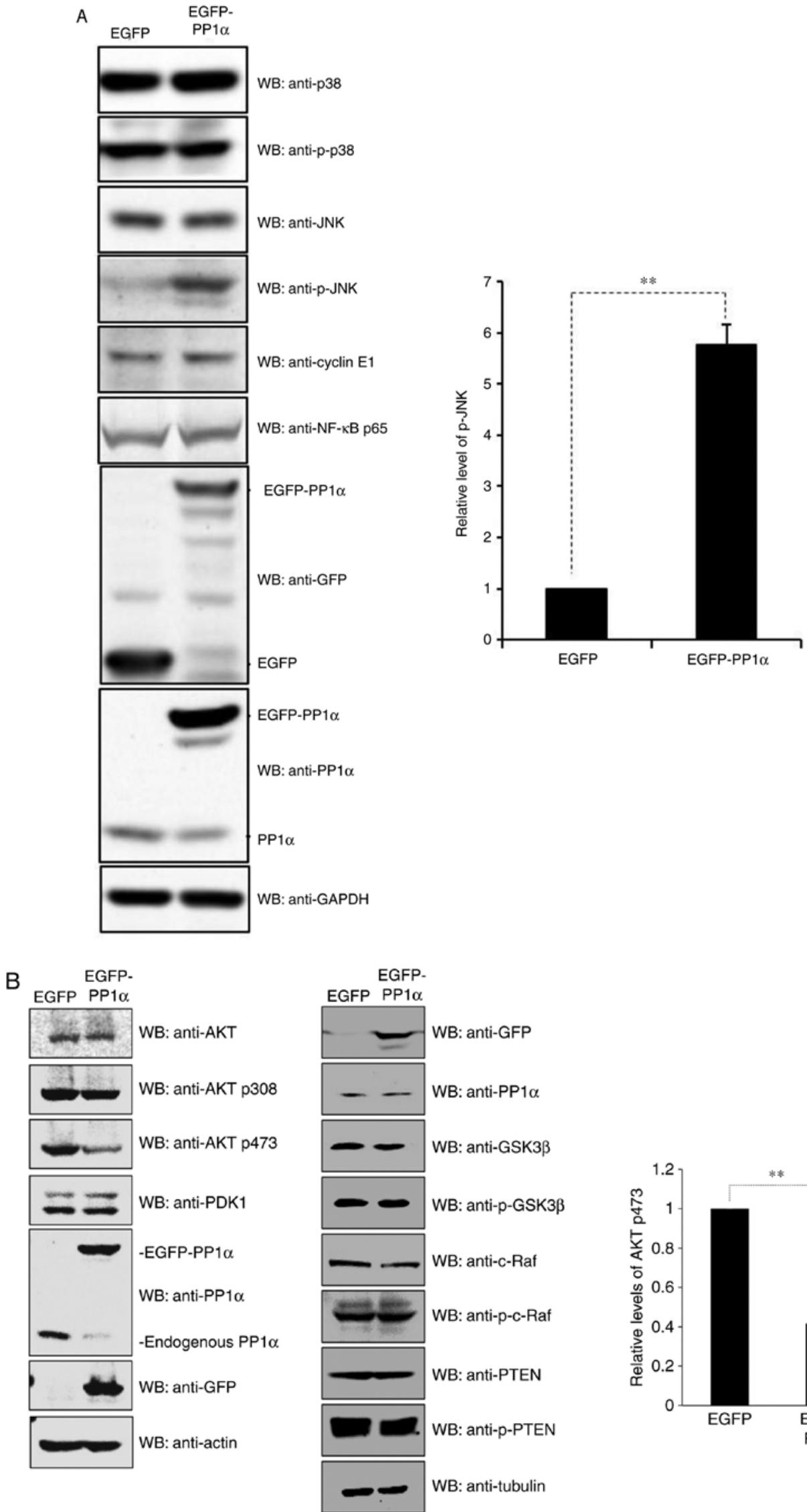
the development of different cancer types. The present study revealed that knockdown of PP1 $\alpha$ attenuated the cell transforming activity and inactivated the AKT signaling cascade. This effect included the decrease in the p-AKT levels at the T473 residue, whereas the MAPK/JNK pathway was not affected in A549 cells. In contrast to these findings, overexpression of PP1 $\alpha$ inhibited cell proliferation, while enhancing the dephosphorylation of HURP. Concomitantly, it inhibited p-JNK levels induced by p-HURP and it increased the levels of p-AKT at the T473 residue in 293T cells. Therefore, PP1 $\alpha$ upregulated p-AKT levels and positively regulated cell transformation in A549 cells. PP1 $\alpha$ downregulation of p-AKT levels increased the expression of p-JNK and inhibited 293T cell proliferation. The data indicated that PP1 $\alpha$ exerted differential growth regulatory effects on A549 and 293T cells via distinct or even opposite mechanisms. PP1 $\alpha$ has been revealed to activate the MAPK pathway in androgen-responsive cell lines, such as PC3 cells (52). In the present study, it was reported that PP1 $\alpha$ inactivated the MAPK cascade by increasing the levels of p-JNK in 293T cells, where the androgen receptor was not expressed in these cell line models (53-55). Therefore, the distinct effect of PP1 $\alpha$ on the MAPK pathway may depend on the androgen levels.

Furthermore, the present study demonstrated the essential role of PP1 $\alpha$ in the maintenance of the cell transforming activity of lung cancer A549 cells. Initially, the overexpression of ectopic PP1 $\alpha$ promoted cell proliferation. Moreover, the silencing of PP1 $\alpha$ impaired cell migration and blocked cell proliferation under normal and low serum conditions, and in the presence of a low number of cells and a cell culture environment that did not allow strong attachment. In addition, PP1 $\alpha$ was revealed to be overexpressed in 15 out of 31 lung cancer tissues. Collectively, the data supported the oncogenic role of PP1 $\alpha$ in lung cancer formation, which is in line with previous studies highlighting that downregulation or inactivation of PP1 $\alpha$ is associated with poor prognosis (24) and radioresistance (25) of lung cancer cells. However, negative correlation of PP1 $\alpha$ with lung cancer has also been reported (23).

\section{Acknowledgements}

We would like to thank Ms. Mei-Chun Liu from the Instrument Center and Ms. Jen Miao at Taichung Veterans General Hospital and Ms. Li-Wen Lee from the Department of Surgery at Taichung Veterans General Hospital for their technical support.

\section{Funding}

The present research was supported by the Taichung Veterans General Hospital-National Chi Nan University Joint Research Program (TCVGH-NCNU1077902 and TCVGH-NCNU1067902), Taichung Veterans General Hospital (TCVGH-1083207C and TCVGH-1083208D), the Ministry of Science and Technology (MOST 105-2320-B-260-001-MY3), and the China Medical University and Hospital grant (DMR-107-116, 108-119) awarded to SCC.

\section{Availability of data and materials}

The datasets used and/or analyzed during the present study are available from the corresponding author on reasonable request.

\section{Ethics approval and consent to participate}

The Institutional Review Board and Human Ethics Committee of Taichung Veterans General Hospital (Taichung, Taiwan) approved the study. All patients signed informed consent for participation in the present study.

\section{Authors' contributions}

KCC, SCC, JYH and CTRY designed the study, collected the literature, analyzed and interpreted the data. CTRY prepared the manuscript and arranged the manpower. JMMC, RYC and YRJH performed the experiments. All authors approved the final manuscript and agree to be accountable for all aspects of the research in ensuring that the accuracy or integrity of any part of the work are appropriately investigated and resolved.

\section{Patient consent for publication}

Not applicable.

\section{Competing interests}

The authors declare that they have no competing interests.

\section{References}

1. Bischoff JR, Anderson L, Zhu Y, Mossie K, Ng L, Souza B, Schryver B, Flanagan P, Clairvoyant F, Ginther C, et al: A homologue of Drosophila aurora kinase is oncogenic and amplified in human colorectal cancers. EMBO J 17: 3052-3065, 1998.

2. Wang X, Zhou YX, Qiao W, Tominaga Y, Ouchi M, Ouchi T and Deng CX: Overexpression of aurora kinase A in mouse mammary epithelium induces genetic instability preceding mammary tumor formation. Oncogene 25: 7148-7158, 2006.

3. Zhou H, Kuang J, Zhong L, Kuo WL, Gray JW, Sahin A, Brinkley BR and Sen S: Tumour amplified kinase STK15/BTAK induces centrosome amplification, aneuploidy and transformation. Nat Genet 20: 189-193, 1998.

4. Fu J, Bian M, Jiang Q and Zhang C: Roles of Aurora kinases in mitosis and tumorigenesis. Mol Cancer Res 5: 1-10, 2007.

5. Katayama H, Brinkley WR and Sen S: The Aurora kinases: Role in cell transformation and tumorigenesis. Cancer Metastasis Rev 22: 451-464, 2003.

6. Chen JM, Chiu SC, Wei TY, Lin SY, Chong CM, Wu CC, Huang JY, Yang ST, Ku CF, Hsia JY and Yu CT: The involvement of nuclear factor- $x$ appaB in the nuclear targeting and cyclin E1 upregulating activities of hepatoma upregulated protein. Cell Signal 27: 26-36, 2015.

7. Yu CT, Hsu JM, Lee YC, Tsou AP, Chou CK and Huang CY: Phosphorylation and stabilization of HURP by Aurora-A: Implication of HURP as a transforming target of Aurora-A. Mol Cell Biol 25: 5789-5800, 2005.

8. Kopnin BP: Targets of oncogenes and tumor suppressors: Key for understanding basic mechanisms of carcinogenesis. Biochemistry (Mosc) 65: 2-27, 2000.

9. Liu CW, Wang RH and Berndt N: Protein phosphatase 1alpha activity prevents oncogenic transformation. Mol Carcinog 45: 648-656, 2006.

10. Berndt N, Dohadwala M and Liu CW: Constitutively active protein phosphatase 1alpha causes Rb-dependent G1 arrest in human cancer cells. Curr Biol 7: 375-386, 1997. 
11. Liu CW, Wang RH, Dohadwala M, Schönthal AH, Villa-Moruzzi E and Berndt N: Inhibitory phosphorylation of PP1alpha catalytic subunit during the G(1)/S transition. J Biol Chem 274: 29470-29475, 1999.

12. Ayllón V, Martínez-AC, García A, Cayla X and Rebollo A Protein phosphatase 1alpha is a Ras-activated Bad phosphatase that regulates interleukin-2 deprivation-induced apoptosis. EMBO J 19: 2237-2246, 2000

13. Dessauge F, Cayla X, Albar JP, Fleischer A, Ghadiri A, Duhamel $\mathrm{M}$ and Rebollo A: Identification of PP1alpha as a caspase-9 regulator in IL-2 deprivation-induced apoptosis. J Immunol 177: 2441-2451, 2006.

14. Eke I, Koch U, Hehlgans S, Sandfort V, Stanchi F, Zips D, Baumann M, Shevchenko A, Pilarsky C, Haase M, et al: PINCH1 regulates Akt1 activation and enhances radioresistance by inhibiting PP1alpha. J Clin Invest 120: 2516-2527, 2010.

15. Wang RH, Liu CW, Avramis VI and Berndt N: Protein phosphatase 1alpha-mediated stimulation of apoptosis is associated with dephosphorylation of the retinoblastoma protein. Oncogene 20: 6111-6122, 2001.

16. Imai Y, Kakinoki Y, Takizawa N, Nakamura K, Shima H and Kikuchi K: Up-regulation of nuclear PP1alpha and PP1delta in hepatoma cells. Int J Oncol 14: 121-126, 1999.

17. Nomoto K, Shibata N,Imai Y,Kitamura K, Nakamura K, Mizuno Y and Kikuchi K: Activation of protein phosphatase lalpha promoter in ascites hepatoma cells. Int J Oncol 13: 331-334, 1998.

18. Takizawa N, Mizuno Y, Saadat M and Kikuchi K: Selective increases in isoform PP1 alpha of type-1 protein phosphatase in ascites hepatoma cells. Jpn J Cancer Res 85: 274-278, 1994.

19. Prowatke I, Devens F, Benner A, Gröne EF, Mertens D, Gröne HJ, Lichter P and Joos S: Expression analysis of imbalanced genes in prostate carcinoma using tissue microarrays. Br J Cancer 96 82-88, 2007

20. Troutaud D, Petit B, Bellanger C, Marin B, Gourin-Chaury MP, Petit D, Olivrie A, Feuillard J, Jauberteau MO and Bordessoule D: Prognostic significance of BAD and AIF apoptotic pathways in diffuse large B-cell lymphoma. Clin Lymphoma Myeloma Leuk 10: 118-124, 2010.

21. Hsu LC, Huang X, Seasholtz S, Potter DM and Gollin SM: Gene amplification and overexpression of protein phosphatase lalpha in oral squamous cell carcinoma cell lines. Oncogene 25: $5517-5526,2006$

22. Mei Y, Liu YB, Cao S, Tian ZW and Zhou HH: RIF1 promotes tumor growth and cancer stem cell-like traits in NSCLC by protein phosphatase 1 -mediated activation of $\mathrm{Wnt} / \beta$-catenin signaling. Cell Death Dis 9: 942, 2018.

23. Chen PC, Li C, Wang D, Luo ZW, Fu SJ, Li X, Li ZL, Chen XW, $\mathrm{Li}$ L, Huang ZX, et al: PP-1 $\alpha$ and PP-1 $\gamma$ display antagonism and differential roles in tumorigenicity of lung cancer cells. Curr Mol Med 13: 220-227, 2013.

24. Verdugo-Sivianes EM, Navas L, Molina-Pinelo S, Ferrer I, Quintanal-Villalonga A, Peinado J, Garcia-Heredia JM, Felipe-Abrio B, Muñoz-Galvan S, Marin JJ, et al: Coordinated downregulation of Spinophilin and the catalytic subunits of PP1, $\mathrm{PPP} 1 \mathrm{CA} / \mathrm{B} / \mathrm{C}$, contributes to a worse prognosis in lung cancer. Oncotarget 8: 105196-105210, 2017.

25. Kim W, Youn H, Kang C and Youn B: Inflammation-induced radioresistance is mediated by ROS-dependent inactivation of protein phosphatase 1 in non-small cell lung cancer cells. Apoptosis 20: 1242-1252, 2015.

26. Liu F, Yang X, Geng M and Huang M: Targeting ERK, an Achilles' Heel of the MAPK pathway, in cancer therapy. Acta Pharm Sin B 8: 552-562, 2018.

27. Mayer IA and Arteaga CL: The PI3K/AKT pathway as a target for cancer treatment. Annu Rev Med 67: 11-28, 2016.

28. Selim KA, Abdelrasoul H, Aboelmagd M and Tawila AM: The role of the MAPK signaling, topoisomerase and dietary bioactives in controlling cancer incidence. Diseases 5 pii: E13, 2017.

29. Carnero A and Paramio JM: The PTEN/PI3K/AKT Pathway in vivo, cancer mouse models. Front Oncol 4: 252, 2014.

30. Garcia-Echeverria C and Sellers WR: Drug discovery approaches targeting the PI3K/Akt pathway in cancer. Oncogene 27: $5511-5526,2008$

31. Robertson BW, Bonsal L and Chellaiah MA: Regulation of Erk1/2 activation by osteopontin in PC3 human prostate cancer cells. Mol Cancer 9: 260, 2010.

32. Shi ZZ, Shang L, Jiang YY, Shi F, Xu X, Wang MR and Hao JJ: Identification of genomic biomarkers associated with the clinicopathological parameters and prognosis of esophageal squamous cell carcinoma. Cancer Biomark 15: 755-761, 2015.
33. Chunli W, Jiajie H, Lifei W, Beiqing $\mathrm{P}$, Xin $\mathrm{X}$, Yan $\mathrm{C}$, Mingrong W and Xuemei J: IGHMBP2 overexpression promotes cell migration and invasion in esophageal squamous carcinoma. Yi Chuan 37: 360-366, 2015 (In Chinese).

34. Sawada G, Niida A, Hirata H, Komatsu H, Uchi R, Shimamura T, Takahashi Y, Kurashige J, Matsumura T, Ueo H, et al: An integrative analysis to identify driver genes in esophageal squamous cell carcinoma. PLoS One 10: e0139808, 2015.

35. Onkes W, Fredrik R, Micci F, Schönbeck BJ, Martin-Subero JI, Ullmann R, Hilpert F, Bräutigam K, Janssen O, Maass N, et al: Breakpoint characterization of the $\operatorname{der}(19) \mathrm{t}(11 ; 19)(\mathrm{q} 13 ; \mathrm{p} 13)$ in the ovarian cancer cell line SKOV-3. Genes Chromosomes Cancer 52: 512-522, 2013

36. Wang L, Wenners A, Hilpert F, Fredrik R, Micci F, Onkes W, Caliebe A, Maass N, Weimer J and Arnold N: Frequent translocations of $11 \mathrm{q} 13.2$ and $19 \mathrm{p} 13.2$ in ovarian cancer. Genes Chromosomes Cancer 53: 447-453, 2014.

37. Sárová I, Březinová J, Zemanová Z, Gančarčíková M, Vydra J, Cermák J and Michalová K: Rearrangement of 11q13.2 region in two patients with acute myeloid leukemia. Leuk Res 37: 479, 2013.

38. Hooker S, Hernandez W, Chen H, Robbins C, Torres JB, Ahaghotu C, Carpten J and Kittles RA: Replication of prostate cancer risk loci on 8q24, 11q13, 17q12, 19q33, and Xp11 in African Americans. Prostate 70: 270-275, 2010.

39. Waters KM, Le Marchand L, Kolonel LN, Monroe KR, Stram DO, Henderson BE and Haiman CA: Generalizability of associations from prostate cancer genome-wide association studies in multiple populations. Cancer Epidemiol Biomarkers Prev 18: 1285-1289, 2009.

40. Bocanegra M, Bergamaschi A, Kim YH, Miller MA, Rajput AB, Kao J, Langerød A, Han W, Noh DY, Jeffrey SS, et al: Focal amplification and oncogene dependency of GAB2 in breast cancer. Oncogene 29: 774-779, 2010.

41. Chunder N, Mandal S, Roy A, Roychoudhury S and Panda CK Analysis of different deleted regions in chromosome 11 and their interrelations in early- and late-onset breast tumors: Association with cyclin D1 amplification and survival. Diagn Mol Pathol 13: $172-182,2004$

42. Weilandt M, Koch A, Rieder H, Deenen R, Schwender H, Niegisch G and Schulz WA: Target genes of recurrent chromosomal amplification and deletion in urothelial carcinoma. Cancer Genomics Proteomics 11: 141-153, 2014.

43. Sia D, Hoshida Y, Villanueva A, Roayaie S, Ferrer J, Tabak B, Peix J, Sole M, Tovar V, Alsinet C, et al: Integrative molecular analysis of intrahepatic cholangiocarcinoma reveals 2 classes that have different outcomes. Gastroenterology 144: 829-840, 2013.

44. Chen CF, Hsu EC, Lin KT, Tu PH, Chang HW, Lin CH, Chen YJ, Gu DL, Lin CH, Wu JY, et al: Overlapping high-resolution copy number alterations in cancer genomes identified putative cancer genes in hepatocellular carcinoma. Hepatology 52: 1690-1701, 2010.

45. Gruel N, Lucchesi C, Raynal V, Rodrigues MJ, Pierron G, Goudefroye R, Cottu P, Reyal F, Sastre-Garau X, Fourquet A, et al: Lobular invasive carcinoma of the breast is a molecular entity distinct from luminal invasive ductal carcinoma. Eur J Cancer 46: 2399-2407, 2010

46. Chang CC, Zhou X, Taylor JJ, Huang WT, Ren X, Monzon F, Feng Y, Rao PH, Lu XY, Fabio F, et al: Genomic profiling of plasmablastic lymphoma using array comparative genomic hybridization $(\mathrm{aCGH})$ : Revealing significant overlapping genomic lesions with diffuse large B-cell lymphoma. J Hematol Oncol 2: 47, 2009.

47. Sarova I, Brezinova J, Zemanova Z, Bystricka D, Krejcik Z, Soukup P, Vydra J, Cermak J, Jonasova A and Michalova K: Characterization of chromosome 11 breakpoints and the areas of deletion and amplification in patients with newly diagnosed acute myeloid leukemia. Genes Chromosomes Cancer 52: 619-635, 2013.

48. Serio G, Gentile M, Pennella A, Marzullo A, Buonadonna AL, Nazzaro P, Testini M, Musti M and Scattone A: Characterization of a complex chromosome aberration in two cases of peritoneal mesothelioma arising primarily in the hernial sac. Pathol Int 59: 415-421, 2009.

49. Senda K, Goi T, Hirono Y, Katayama K and Yamaguchi A: Analysis of RIN1 gene expression in colorectal cancer. Oncol Rep 17: 1171-1175, 2007. 
50. Boukamp P, Popp S, Bleuel K, Tomakidi E, Bürkle A and Fusenig NE: Tumorigenic conversion of immortal human skin keratinocytes $(\mathrm{HaCaT})$ by elevated temperature. Oncogene 18: 5638-5645, 1999.

51. Llorian M, Beullens M, Andrés I, Ortiz JM and Bollen M: SIPP1, a novel pre-mRNA splicing factor and interactor of protein phosphatase-1. Biochem J 378: P229-P238, 2004.

52. Chen M, Wan L, Zhang J, Zhang J, Mendez L, Clohessy JG, Berry K, Victor J, Yin Q, Zhu Y, et al: Deregulated PP1 $\alpha$ phosphatase activity towards MAPK activation is antagonized by a tumor suppressive failsafe mechanism. Nat Commun 9: 159, 2018.
53. Chen PH, Tsao YP, Wang CC and Chen SL: Nuclear receptor interaction protein, a coactivator of androgen receptors (AR), is regulated by $\mathrm{AR}$ and $\mathrm{Sp} 1$ to feed forward and activate its own gene expression through AR protein stability. Nucleic Acids Res 36: 51-66, 2008.

54. Yang Y, Tse AK, Li P, Ma Q, Xiang S, Nicosia SV, Seto E, Zhang $\mathrm{X}$ and Bai $\mathrm{W}$ : Inhibition of androgen receptor activity by Histone deacetylase 4 through receptor SUMOylation. Oncogene 30: 2207-2218, 2011

55. Wei TY, Hsia JY, Chiu SC, Su LJ, Juan CC, Lee YC, Chen JM, Chou HY, Huang JY, Huang HM and Yu CT: Methylosome protein 50 promotes androgen- and estrogen-independent tumorigenesis. Cell Signal 26: 2940-2950, 2014. 